The moderating effects of inner-directed and other-directed behavior styles on the relationship between organizational commitment and organizational citizenship behavior

\author{
Besharat, Mohammad Ali $\bowtie$ \\ University of Tehran,Iran (besharat@ut.ac.ir) \\ Pourbohlool, Samane \\ University of Tehran, Iran (bohlool6385@gmail.com)
}

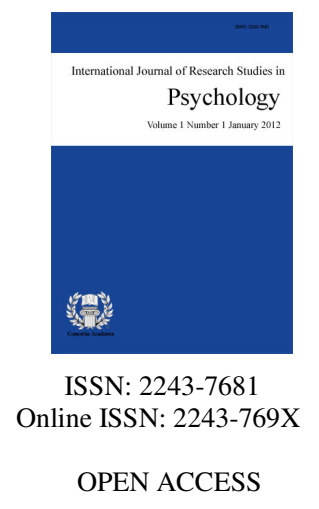

Received: 14 May 2013

Revised: 26 October 2013

Available Online: 5 November 2013

DOI: $10.5861 /$ ijrsp.2013.459

Accepted: 27 October 2013

\title{
Abstract
}

The aim of the present study was to investigate the moderating effects of inner-directed and other-directed behavior styles on the association between organizational commitment and organizational citizenship behavior in a sample of Iranian bank employees. A total of 249 volunteer employees (140 males, 109 females) were included in this study. All participants were asked to complete Organizational Commitment Scale (OCS), Organizational Citizenship Behavior Scale (OCBS), and Personal Behavior Styles Scale (PBSS). The results revealed that inner-directed and other-directed behavior styles moderated the relationship between organizational commitment and organizational citizenship behavior. Inner-directed style amplified the relationship between organizational commitment and organizational citizenship behavior, whereas other-directed style showed an opposite impact on this relationship. It can be concluded that inner-directed individuals experience strong sense of control on their daily life events and do not have need to reinforcement and control from the organization. Whereas, other-directed individuals experience lack of control and they have strong need to reinforcement and supervision from outside.

Keywords: behavior style; organizational commitment; organizational behavior; behavior control; reinforcement 


\section{The moderating effects of inner-directed and other-directed behavior styles on the relationship between organizational commitment and organizational citizenship behavior}

\section{Introduction}

Organizational commitment and its effect on the organizational extra-role behaviors is one of the important subjects in the field of industrial and social psychology. Organizational commitment reflects the individual's attitude towards his/her organization. It is determined by strong belief and acceptance of organization values (value commitment) and considerable effort in favor of the organization along with commitment to stay as a member of the organization (Gebremichael \& Prasada Rao, 2013, Herscovitch \& Meyer, 2002; Mamman, Kamoche \& Bakuwa, 2012; Meyer, Stanley, \& Parfyonova, 2012; Reade \& Lee, 2012). Meyer and Allen's (1990) three components model for organizational commitment resulted in numerous experimental studies. Three components of this model include affective, normative, and continuance commitment (Meyer, Stanley, Jackson, Mclnnis, Maltin, \& Sheppard, 2012). Affective commitment has been defined as individual's sense of belonging to the organization. Employees with high levels of affective commitment are loyal to the organization's goals and values. They take responsibility for the actualization of these goals (Meyer et al., 2012; Sinclair, Tucker, \& Cullen, 2006).

In normative commitment, employee remains in the organization since he/she is committed to the organization's norms and code of ethics. Employee does not leave the organization because of others' judgment (e.g., employer and counterparts). These employees do not experience affective attachment or belonging to the organization (Ozag \& Dugoma, 2003). In continuance commitment, individual remains in the organization since changing occupation and organization is demanding and may interfere with his/her occupational procedure. It means that individual decides to remain in the organization based on the product of Profit-Cost analysis (Meyer \& Allen, 1991; Meyer et al., 2012). Based on Steers and Rhodes's (1978) withdrawal theory, committed employees tend to less absenteeism since it may endanger their membership in the organization. Research findings revealed that when employees internalize the organization's perspectives and goals, they experience more commitment and also have more tendencies to perform organizational citizenship behavior. Morrison (1994) assessed employees' affective and normative commitment and concluded that affective commitment has positive relation with all dimensions of organizational citizenship behavior, whereas normative commitment is related to some dimensions of organizational citizenship behavior. To summarize, research evidence emphasize that all dimensions of organizational commitment have significant relation with organizational citizenship behavior, although affective commitment is the most important factor in predicting employees' organizational citizenship behaviors (Bogler \& Somech, 2004; Dunham, Crub, \& Castanda, 1994).

Organizational citizenship behavior is performed by the employees as a result of their personal choice and is not directly or explicitly recognized by formal rewarding system of the organization and in general, improves the effective functioning of the organization (Kernodle \& Noble, 2013; Mamman et al., 2012; Organ, 1988; Orgn, Podsakoff \& Mackenzie, 2006; Tanaka, 2013; Will, 2012). Common antecedents of organizational citizenship behavior have been divided into personality, attitudes, and organizational factors which interact with each other in the outbreak of organizational citizenship behavior (Al-Sharafi \& Rajiani, 2013; Lee, Kim \& Kim, 2013; Podsakoff, Mackenzie, Paine, \& Bachrach, 2000; Raymond \& Mjoli, 2013)). Organ (1988) whom established his theory of organizational citizenship behavior based on the personality theories, believed that personality factors can bridge between occupational attitudes and organizational citizenship behavior.

Research evidences demonstrate that psychological and personality factors are important variables which affect organizational attitudes and extra-role behaviors. For example, personality characteristics like 
The moderating effects of inner-directed and other-directed behavior styles

introversion-extraversion dimensions have significant relation with organizational commitment (Erdheim, Wang, \& Zickar, 2006). Research findings revealed that several other psychological variables might affect the extent of employees' vocational attitudes and behaviors (e.g., Carpenter, 2008; Chein, 2004; Jay, 2008). In other studies, the association between perceived control and organizational behaviors has been confirmed (Moon, Kamdar, Mayer, \& Takeuchi, 2008). Researchers concluded that perceived control has significant relation with organizational commitment, job satisfaction and extra-role behaviors (e.g., Deifendorf, Brown, Kamin, \& Lord, 2002; Kircaldy, Shephard, \& Furnham, 2002; Lin, 2006). Research findings revealed that individuals with internal locus of control rather than externals are more likely tend to perform organizational citizenship behavior. Sense of control and efficacy has positive relation with organizational citizenship behavior since individuals perform helping behaviors when they feel that behaviors will be effective (Spector \& Fox, 2002).

Collins and colleagues (1973) examined Rotter's (1966) internal-external locus of control and found it more complex than what Rotter supposed. They invented a multidimensional scale for personal behavior styles which include four dimensions related to appraisal of the world; other-directed behavior, inner-directed behavior, lack of constraint on behavior, and predictability of behavior. Like Rotter's externals, other-directed individuals tend to satisfy other's expectations and experience inability to control their life direction. On the other hand, inner-directed individuals have an internal map which directs their behaviors. These individuals like Rotter's internals, have obvious sense of direction and control. Lack of constraint on behavior demonstrates individuals' creativity and self-actualization. Predictability of behavior points to individuals' ability to give sense to the world. These individuals believe that their life is secure and predictable (Janda, 2001).

Overall, research literature in the domain of organizational citizenship behavior indicates that in addition to organizational variables like organizational commitment and job involvement, personality and psychological variables have considerable effects on the amount of employees' extra-role behaviors. But the nature of such influences remained unclear and needs to be addressed. It is worthy to investigate the moderating role of such important psychological factors in the domain of organizational behavior in order to clarify the nature of association between psychological factors and organizational attitudes and behaviors, especially extra-role behaviors like organizational citizenship behavior. In this direction, we assume that sense of control as personality component of perceived control might affect the amount of employees' positive job attitudes and also maximizes the likelihood of employees' tendency to perform organizational citizenship behavior. Given that personal behavior styles refer to how confident an individual is in his/her capability to control life direction and events, it might have a different effect on the relationship between organizational commitment and organizational citizenship behavior.

This study is innovative due to its focus on moderating effect of personal behavior styles on the association between organizational commitment and organizational citizenship behavior whereas previous studies in this domain mostly focus on unilateral direction (e.g., Akhter, Ghayas, \& Adill, 2013; Deifendorf, Brown, Kamin, \& Lord, 2002; Kircaldy, Shephard, \& Furnham, 2002; Lin, 2006, Moon, Kamdar, Mayer, \& Takeuchi, 2008; Spector \& Fox, 2002). Aside from this, replacing two-dimensional locus of control with personal behavior styles in order to examine sense of perceived control more precisely than before is one of the most advantages of this exploratory research.

The main aim of the present study was to examine the moderating role of inner-directed and other-directed behavior styles on the association between organizational commitment and organizational citizenship behavior in a sample of Iranian bank employees. By considering theoretical and research findings in this field, there are two hypotheses for this study: 1) There is a positive relationship between organizational commitment and organizational citizenship behavior; 2) inner-directed and other-directed behavior styles have a moderating role on the relationship between organizational commitment and organizational citizenship behavior. 


\section{Method}

\subsection{Participants and Procedure}

The participants were government Iranian bank employees. We used voluntary sampling method in this study. Accordingly, two hundred and forty nine employees (140 males, $\mathrm{M}_{\mathrm{age}}=34.49$, age range: 22-59 years, 109 females, $M_{\text {age }}=30.44$, age range: 20-53 years) from different branches of Saderat, Maskan, Melli, and Mellat banks participated in this study voluntarily. In coordination with authorities of any branches, we first clarified some aspects of the research process for participants and then we asked them to complete the research questionnaires. There was no time limitation, but the maximum time did not exceed 20 minutes. The aim was that employees answer to the questionnaire relaxed and precise without the pressure of time limitation in order to increase accuracy and reliability of the answers.

\subsection{Measures}

Organizational Commitment Scale (OCS). This is an 18-item questionnaire which has been developed to measure organizational commitment (Mowday, Steers, \& Porter, 1979). The items measure affective, normative and tylproperties of the OCS have been examined and confirmed in Iranian population (Gholipour, 2008). Based on preliminary findings in a sample of 300 employees from different organizations, calculated Cronbach's alpha coefficients for three subscales were $.78, .88$, and .81 , respectively. This is indicative of adequate internal consistency of the measure.

Organizational Citizenship Behavior Scale (OCBS). This is a 12-item questionnaire which has been derived from previous measures of organizational citizenship behaviors (Organ, 1988) and validated for the purpose of measuring organizational citizenship behavior in Iranian employees. The items measure organizational citizenship behavior in a five-point Likert-type scale from 1 (very little) to 5 (very much). Psychometric properties of OCBS have been examined and confirmed (Gholipour, 2008). Based on preliminary findings in a sample of 300 employees from different organizations, calculated Cronbach's alpha coefficients for the scale was .72. This is indicative of adequate internal consistency of the measure. Test-retest correlation coefficients among the scores of 150 participants were calculated in two occasions with time duration of $2-4$ weeks. It was .78 and confirmed test-retest reliability of the OCBS at $p<.001$.

Personal Behavior Styles Scale (PBSS). This is a 29-item instrument which measures four dimensions of personal behavior styles (Collins, Martin, Ashmore, \& Ross, 1973). The items measure of personal behavior styles including inner-directed, other-directed, lack of constraint in behavior and predictability of behavior in a five-point Likert-type scale from 1 (very little) to 5 (very much). Psychometric properties of the PBSS have been examined and confirmed in Iranian population (Besharat, 2006). Based on preliminary findings, calculated Cronbach's alpha coefficients for the four subscales was $.94, .90, .86$, and .93 , respectively. This is indicative of adequate internal consistency of the questionnaire. Test-retest correlation coefficients among the scores of 123 participants were calculated in two occasions with time duration of $2-4$ weeks. They were $.77, .81, .87$, and .84, respectively and confirmed test-retest reliability of the questionnaire at $p<.001$.

\subsection{Statistical analysis}

Firstly, associations among organizational citizenship behavior, organizational commitment (affective, normative, and continuance), inner-directed and other-directed styles were examined using Pearson's correlation coefficients. Secondly, series of two step regression analyses were conducted to examine moderating effects of inner-directed and other-directed behavior styles on the association between organizational commitment and organizational citizenship behavior. 
The moderating effects of inner-directed and other-directed behavior styles

\section{Results}

Mean scores and standard deviations for all scales are presented for males, females and the total sample in Table1.

\section{Table 1}

Mean scores and standard deviations on each scale of the organizational citizenship behavior, organizational commitment, inner-directed, other-directed, for male, female and the total sample

\begin{tabular}{llll}
\hline Variables/scale & Male: M(SD) & Female: M(SD) & Total: M(SD) \\
\hline Organizational Citizenship behavior & $47.92(5.75)$ & $48.16(5.47)$ & $48.02(5.62)$ \\
Organizational commitment & $63.15(9.20)$ & $62.40(9.12)$ & $62.82(9.15)$ \\
Affective commitment & $26.12(4.42)$ & $25.92(4.44)$ & $26.03(4.42)$ \\
Continuance commitment & $19.69(3.67)$ & $20.29(3.25)$ & $19.95(3.50)$ \\
Normative commitment & $17.33(3.45)$ & $16.18(3.73)$ & $16.83(3.62)$ \\
Inner-directed & $22.27(3.64)$ & $22.44(3.20)$ & $22.60(3.45)$ \\
Other-directed & $24.64(8.60)$ & $23.79(7.78)$ & $24.27(8.25)$ \\
\hline
\end{tabular}

Results of the Pearson correlations showed that there are significant correlations between organizational commitment, inner-directed and other-directed behavior styles with organizational citizenship behavior scores. These results confirm the first research hypothesis.

\section{Table 2}

Pearson product moment correlations between measures of organizational citizenship behavior, organizational commitment, inner-directed, other directed lack of constraint on behavior, and predictability of behavior

\begin{tabular}{|c|c|c|c|c|c|c|c|}
\hline Measures & 1 & 2 & 3 & 4 & 5 & 6 & 7 \\
\hline 1. Organizational citizenship behavior & 1 & & & & & & \\
\hline 2. Organizational commitment & .45 & 1 & & & & & \\
\hline 3. Affective commitment & .46 & .85 & 1 & & & & \\
\hline 4. Normative commitment & .30 & .76 & .49 & 1 & & & \\
\hline 5. Continuance commitment & .30 & .74 & .46 & .39 & 1 & & \\
\hline 6. Inner-directed style & .30 & .20 & .18 & .20 & .12 & 1 & \\
\hline 7. Other-directed style & -.25 & -.19 & -.19 & -.17 & -.17 & -.05 & 1 \\
\hline
\end{tabular}

Note. $p<.05$

Then, a series of two steps regression analyses were conducted to examine the moderating effects of inner-directed and other-directed behavior styles on the association between organizational commitment and organizational citizenship behavior. The results of these analyses are shown in Table 3. These results revealed that with entering inner-directed style as a moderating variable in regression equation, the $\beta$ coefficient for organizational commitment decreased from .45 to .30 and organizational commitment remained significant $(t=$ $8.12, p<.001)$. These results reveal that inner-directed style could affect the relationship between organizational commitment and organizational citizenship behavior. 
Besharat, M. A. \& Pourbohlool, S.

\section{Table 3}

Summary of regression analysis for moderation effects of inner-directed and other-directed behavior styles on the relationship between organizational commitment and organizational citizenship behavior

\begin{tabular}{|c|c|c|c|c|c|}
\hline Variable & B & SEB & $\beta$ & $t$ & $p$ \\
\hline \multicolumn{6}{|l|}{ Step1 } \\
\hline Organizational commitment $\left(\mathrm{R}^{2}=.21\right)$ & .28 & .035 & .45 & 8.12 & .001 \\
\hline \multicolumn{6}{|l|}{ Step 2} \\
\hline \multicolumn{6}{|l|}{ Organizational commitment } \\
\hline Inner-directed style $\left(\mathrm{R}^{2}=.29, \Delta \mathrm{R}^{2}=.08\right)$ & .49 & .08 & .30 & 5.55 & .001 \\
\hline \multicolumn{6}{|l|}{ Step1 } \\
\hline Organizational commitment $\left(\mathrm{R}^{2}=.21\right)$ & .28 & .03 & .45 & 8.16 & .001 \\
\hline \multicolumn{6}{|l|}{ Step 2} \\
\hline Organizational commitment & -.09 & .03 & -.14 & -2.55 & .011 \\
\hline Other-directed style $\left(\mathrm{R}^{2}=.23, \Delta \mathrm{R}^{2}=.03\right)$ & & & & & \\
\hline
\end{tabular}

A series of two regression analyses were also conducted in order to examine the moderating effect of other-directed style on the association between organizational commitment and organizational citizenship behavior. The results of these analyses are shown in Table 3. These results revealed that with entering other-directed style as a moderating variable in regression equation, the $\beta$ coefficient for organizational commitment decreased from .45 to -.14. These results reveal that other-directed style could affect the relationship between organizational commitment and organizational citizenship behavior. These results confirm the second research hypothesis.

\section{Discussion}

The present study was undertaken to gain a better insight into the relationship between organizational commitment and organizational citizenship behavior in a sample of Iranian bank employees. In particular, this study examined the moderating effects of inner-directed and other-directed behavior styles on the association between organizational commitment and organizational citizenship behavior. Results of the present study showed that inner-directed style and organizational commitment had significant positive correlations with organizational citizenship behavior. Other-directed style had a significant negative correlation with organizational citizenship behavior. Among the three dimensions of commitment, affective commitment had the higher positive correlation with organizational citizenship behavior. Confirming the first research hypothesis, these findings are in line with the results obtained in previous studies (Ackfedlt \& Coote, 2005; Bogler \& Somech, 2004; Kirkcaldy et.al., 2002; Morrison, 1994; Rioch, 2009).

Moreover, the results of the present study revealed that inner-directed and other-directed styles had moderating effects on the association between organizational commitment and organizational citizenship behavior. Statistical analysis of data indicated that inner-directed style can amplify the positive association between organizational commitment and organizational citizenship behavior. Confirming the second research hypothesis, these results are in line with those studies related to moderating or mediating effects of some personality and organizational variables on the association between organizational citizenship behavior and other occupational and organizational attitude (e.g., Devasagayam, 2013, Zulkarnain, 2013). In addition to this, the result of Abo Elanain's (2007) research revealed that some dimension of personality could moderate the association between organizational commitment and organizational citizenship behavior. These findings might be explained based on the following possibilities. 
Organizational citizenship behavior is a voluntary behavior which is not mentioned in formal task requirements and it is performed by the individual in order to assist the organization (Gebremichael \& Prasada Rao, 2013; Schnake \& Dumler, 2003). At the other hand, commitment with any aspect of daily activity is accompanied with positive personal and social outcomes. At the occupational level, positive identification with one's own job represent the importance of that job in individual's life and impact of the job on the individual's self-concept and also associate with high levels of job satisfaction (Brown, 1996; Raymond \& Mjoli, 2013). Individuals with high levels of commitment are attached to their organization and the organization is a part of their occupational identity. Therefore, they accept organizational goals and values and do their best in order to support these values.

Based on Steers \& Rhodes's withdrawal theory (1978) one can mention another explanation. Committed employees usually experience more job satisfaction and find their jobs mentally satisfactory. This satisfaction is accompanied with the motivation for performing autonomic behaviors in favor of the organization. Based on this, committed employees are more likely tend to perform extra-role behaviors since this might enhance their membership in the organization and maintaining as the organization member is of the most importance for committed employees. Committed employees take responsibility for positive and negative outcomes of their activities in the organization. These individuals are highly motivated for representing a positive image of their occupation and organization.

The results revealed that internal locus of control had a positive relation with positive organizational attitudes and behaviors, whereas external locus of control had a negative association with these attitudes and behaviors. Individuals with strong sense of control are active and agent. They take important responsibilities (Rioch, 2009). These individuals are autonomous and creative, have more successful social and interpersonal relationships and experience high levels of well-being (April, Dharani, \& Peters, 2012). Like internals, inner-directed individuals take more responsibility in social context since they perceive control on their daily life events. Their internal map manages their behavior rather than external factors and forces (Janda, 2001). Since these individuals have more sense of dominance on their life issues, they are certain about their own sufficient resource to achievement and do not need external control and supervision. Sense of control and self-efficacy has a positive relation with organizational citizenship behavior.

In general, when individuals feel that they can be effective, they are more likely tend to perform helping behaviors (Spector \& Fox, 2002). Conversely, individuals with external locus of control perceive no control on their life issues. Like externals, other-directed individuals tend to satisfy others' expectation and are unable to control their own life direction (Janda, 2001). At the occupational level, they are less likely ended to perform autonomic behaviors without organizational supervision. The results of the present study revealed that inner-directed and other-directed styles affected the association between organizational commitment and organizational citizenship behavior. Therefore, committed employees with inner-directed style have more tendencies to perform organizational citizenship behavior. It means that inner-directed style amplifies the effect of organizational commitment on employees' organizational citizenship behavior. Committed employees with other-directed behavior style experience lack of control on their life issues, have fewer tendencies toward organizational citizenship behaviors. In other words, other-directed style attenuates the effect of organizational commitment on employees' organizational citizenship behavior.

\subsection{Implications}

The present findings may have important theoretical and practical implications. At the theoretical level, research findings can lead to further understanding factors contributing to the outbreak and continuance of organizational citizenship behaviors among employees. It can also exhibit a new path to investigate the interplay between psychological and organizational variables in stimulating extra-role behaviors for those researchers interested in launching further research projects in this field. At the practical level, these findings can help organizational managers to establish effective strategies to enrich the vocational atmosphere and empower their 
Besharat, M. A. \& Pourbohlool, S.

employees. In addition, initiating training programs for employees in order to empowering them can intensify their sense of control and autonomy and thereby intensify employees' positive attitudes towards their job and organization. These positive attitudes cause more likelihood of performing extra-role behaviors by employees and amplify the effectiveness in the organizational context.

\subsection{Limitations}

The findings of the present study have several limitations. The cross-sectional design of this study does not allow drawing conclusion about the direction of causality between variables investigated. These data were based upon a sample of volunteer governmental bank employees. This further undermines the generalizability of the result. To evaluate the relationship between organizational commitment and organizational citizenship behavior, it is important to examine the role of other possible moderator variables such as coping strategies and defense mechanisms. Additionally, it is recommended for better understanding the effects of organizational commitment and organizational citizenship behavior, the relationship between these two variables must be examined in samples of different organizations.

\section{References:}

Abo Elanain, H. A. (2007). Relationship between personality and organizational citizenship behavior. International Review of Business Research Papers, 3, 31-34.

Ackfeldt, A. L., \& Coote, L. V. (2005). A study of organizational citizenship behaviors in a retail setting. Journal of Business Research, 58, 151-159. http://dx.doi.org/10.1016/S0148-2963(03)00110-3

Akhter, S., Ghayas, S., \& Adill, A. (2013). Self-efficacy and optimism as predictors of organizational commitment among bank employees. . International Journal of Research Studies in Psychology, 2(2), 33-42. http://dx.doi.org/10.5861/ijrsp.2012.131

Allen, N. J., \& Meyer, J. P. (1990). The measurement and antecedents of affective, continuance and normative commitment to organization. Journal of Occupational Psychology, 63, 1-18. http://dx.doi.org/10.1111/j.2044-8325.1990.tb00506.x

Al-Sharafi, H., \& Rajiani, L. (2013). Promoting organizational citizenship behavior among employees: the role of leadership practices. International Journal of Business and Management, 8, 47-54.

April, K. A., Dharani, B., \& Peters, K. (2012). Impact of locus of control expectancy on level of well-being. Review of European Studies, 4, 124-137. http://dx.doi.org/10.5539/res.v4n2p124

Besharat, M.A. (2006). Reliability and validity of the personal behavior styles scale. Tehran: University of Tehran.

Bogler, R., \& Somech, A. (2004). Influence of teacher empowerment on teacher's organizational commitment and organizational citizenship behavior. Teaching and Teacher Education, 20, 277-289. http://dx.doi.org/10.1016/j.tate.2004.02.003

Brown, S. P. (1996). A Meta-analysis and review of organizational research on job involvement. Psychological Bulletin, 120, 235-255. http://dx.doi.org/10.1037/0033-2909.120.2.235

Carpenter, J. D. (2008). Relating proactive personality and the Big Five to organizational citizenship behavior. Tennessee: University of Tennessee at Chattanooga.

Chein, M. (2004). An investigation of relationship of organizational structure, employees' personality and organizational citizenship behavior. Journal of American Academy of Business, 5, 4280-430.

Collins, B. E., Martin, J. C., Ashmore, R. D., \& Ross, L. (1973). Some dimensions of internal-external metaphor in theories of personality. Journal of Personality, 41, 472-492. http://dx.doi.org/10.1111/j.1467-6494.1973.tb00107.x

Deifendorf, J. M., Brown, D. J, Kamin, A. M., \& Lord, R. G. (2002). Examining the role of involvement in predicting organizational citizenship behavior. Journal of Organizational Behavior, 23, 93-108. http://dx.doi.org/10.1002/job.123

Devasagayam, H. C. (2013). Organizational citizenship behavior of distributed teams: A study of the mediating 
The moderating effects of inner-directed and other-directed behavior styles

effects of organizational justice in software organizations. International Journal of Scientific and Engineering Research, 4, 1-51.

Dunham, R. B., Crub, J. A., \& Castaneda, M. B. (1994). Organizational commitment: The ability of an integrative definition. Journal of Applied Psychology, 79, 370-380.

http://dx.doi.org/10.1037/0021-9010.79.3.370

Erdheim, J., Wang, M., \& Zickar, M. J. (2006). Linking the Big Five personality constructs to organizational commitment. Personality and Individual Differences, 41, 959-970.

http://dx.doi.org/10.1016/j.paid.2006.04.005

Gebremichael, H., \& Prasada Rao, B. V. (2013). Job satisfaction and organizational commitment between academic staff and supporting staff (Volaita Sodo University-Ethiopia as a case). Far East Journal of Psychology and Business, 11, 11-32.

Gholipour, A. (2008). Organizational behavior management. Tehran: Samt Publications. [Farsi]

Herscovitch, L., \& Meyer, J. P. (2002). Commitment to Organizational Change: Extension of three component model. Journal of Applied Psychology, 87, 474-487. http://dx.doi.org/10.1037/0021-9010.87.3.474

Janda, L. (2001). The psychologist's book of personality tests. New York.

Jay, S. (2008). Situation constraints and personality as antecedents of organizational citizenship behavior. Clemson University.

Kernodel, T. A., \& Noble, D. (2013). Organizational citizenship behavior: its importance in academics. American Journal of Business Education, 6 235-240.

Kircaldy, B. D., Shephard, R. J, \& Furnham, A. F. (2002). The influence of type A behavior and locus of control upon job satisfaction and occupational health. Personality and Individual Differences, 33, 1361-1371. http://dx.doi.org/10.1016/S0191-8869(02)00018-1

Lee, U. H., Kim, H. K., \& Kim, Y. H. (2013). Determinants of organizational citizenship behavior and its outcomes. Global Business and Management: An International Journal, 5, 54-65.

Lin, W. B. (2006). The exploration of employee involvement model. Expert System with Application, 31, 69-82. http://dx.doi.org/10.1016/j.eswa.2005.09.035

Mamman, A., Kamoche, K., \& Bakuwa, R. (2012). Diversity, organizational commitment and organizational citizenship behavior: An organizing framework. Human Resource Management Review, 22, 285-302. http://dx.doi.org/10.1016/j.hrmr.2011.12.003

Meyer, J. P., \& Allen, N. J. (1991). A three component conceptualization of organizational commitment. Human Resource Management, 1, 61-89. http://dx.doi.org/10.1016/1053-4822(91)90011-Z

Meyer, J. P., Stanley, D. J., \& Parfyonova, N. M. (2012). Employee commitment in context: the nature and implication of commitment profiles. Journal of Vocational Behavior, 80, 1-16. http://dx.doi.org/10.1016/j.jvb.2011.07.002

Meyer, J. P., Stanley, D. J., Jackson, T. A., Mclnnis, K. J., Maltin, E. R., \& Sheppard, L. (2012). Affective, normative and continuance commitment levels across cultures. Journal of Vocational Behavior, 80, 225-245. http://dx.doi.org/10.1016/j.jvb.2011.09.005

Moon, H., Kamdar, D., Meyer, D. M \& Takeuchi, R (2008). Me or we? The role of personal and as other centered antecedents to innovative citizenship behavior within organizations. Journal of Applied Psychology, 93, 84-94. http://dx.doi.org/10.1037/0021-9010.93.1.84

Morrison, E. W. (1994). Role definition and organizational citizenship behavior. Academy of Management Journal, 37, 1543-1567. http://dx.doi.org/10.2307/256798

Mowday, R. Steers, R., \& Porter, L (1979). The measurement of organizational commitment. Journal of Vocational Behavior, 28, 1530-1556.

Organ, D. W. (1988). Organizational citizenship behavior: The Good Solider Syndrome. Lexington, MA: Lexington books.

Organ, D. W., Podsakoff, P. M. \& Mackenzie, S. B. (2006). Organizational citizenship behavior, its nature, antecedents and consequences. Sage Publication, CA: Thousand Oak.

Ozag, D., \& Dugma, B. (2003). The relationship between cognitive process and perceived usefulness. Human Research Management Review, 13, 1-24. 
Besharat, M. A. \& Pourbohlool, S.

Podsakoff, P. M., Mackenzie, S. B., Paine, J. B., \& Bachrach, D. G. (2000). Organizational citizenship behaviors: A critical review of the theoretical and future research. Journal of Management, 26, 513-563. http://dx.doi.org/10.1177/014920630002600307

Raymond, T. \& Mjoli, T. Q. (2013). The relationship between job involvement, job satisfaction and organizational commitment among lower level employees at a motor-car manufacturing company in Eastern London, South Africa. Journal of Business \& Economic Management, 6, 25-35.

Read, C., \& Lee, H. J. (2012). Organizational commitment in time of war: assessing the impact and attenuation of employee sensitivity to Ethno political conflict. Journal of International Management, 18, 85-101. http://dx.doi.org/10.1016/j.intman.2011.09.002

Rioch, S. (2009). An examination of self-determination and locus of control in adolescents and without learning disabilities. Unpublished master thesis, Canada, University of Calgary.

Rotter, J. (1966). Generalized expectancies for internal versus external control of reinforcement. Psychological Monograph, 80, 609. http://dx.doi.org/10.1037/h0092976

Schnake, M. E., \& Dumler, M. P. (2003). Levels of measurement and analysis issues in organizational cirtizenship behavior research. Journal of Occupational and Organizational Psychology, 76, 283-301. http://dx.doi.org/10.1348/096317903769647184

Sinclair, R., Tucker, J. S., \& Cullen, J. C. (2006). Performance differences among four organizational commitment profiles. Journal of Applied Psychology, 68, 655-663.

Spector, P. E., \& Fox, S. (2002). An emotion-centered model of voluntary work behavior, some parallels between counterproductive work behavior and organizational citizenship behavior. Human Research Management Review, 12, 269-292. http://dx.doi.org/10.1016/S1053-4822(02)00049-9

Steers, R. M., \& Rhodes, S. R. (1978). Major influences on employee attendance: A process model. Journal of Applied Psychology, 46, 259-293.

Tanaka, K. (2013). Organizational citizenship behavior in contemporary workplace in Japan. Japan Labor Review, 10, 5-18.

Will, T. (2012). Enlightenment political philosophy and organizational citizenship behavior: contextualizing historical discourses. Management and Organizational History, 7, 285-302. http://dx.doi.org/10.1177/1744935912457623

Zulkarnain, A. (2012). The mediating effect of quality of work life on the relationship between career development and psychological well-being. International Journal of Research Studies in Psychology, 2(3), 1-14. http://dx.doi.org/10.5861/ijrsp.2013.259 